\title{
Penerapan Haar Cascade Classification Model untuk Deteksi Wajah, Hidung, Mulut, dan Mata Menggunakan Algoritma Viola-Jones
}

\author{
Nono Heryana \\ Universitas Singaperbangsa Karawang \\ Karawang, Indonesia \\ nono@unsika.ac.id
}

\author{
Rini Mayasari \\ Universitas Singaperbangsa Karawang \\ Karawang, Indonesia \\ rini.mayasari@staff.unsika.ac.id
}

\author{
Kiki Ahmad Baihaqi \\ Universitas Buana Perjuangan Karawang \\ Karawang, Indonesia \\ kikiahmad@ubpkarawang.ac.id
}

\begin{abstract}
Penelitian ini dilakukan untuk melakukan deteksi fitur yang ada pada wajah manusia, pendekatan yang digunakn dalam penelitian ini adalah Penerapan Haar Cascade Classification Model untuk Deteksi Wajah, Hidung, Mulut, Mata Menggunakan Algoritma Viola-Jones sehingga sistem yang dihasilkan mampu untuk melakukan deteksi terhadap fitur-fitur yang ada pada wajah manusia yang meliputi Wajah, Hidung, Mulut, dan Mata. Dalam penerapan deteksi wajah, hidung, mulut dan mata ini dibangun menggunakan metode viola-jones yang terdiri dari metode haar-like feature, citra integral, adaboost, dan cascade of classifier. Teknologi pengenalan wajah, Deteksi wajah, hidung dan mulut juga menjadi hal yang penting dalam teknologi pengenalan wajah..
\end{abstract}

Kata kunci - deteksi wajah, haarcascade classification, viola-jones

\section{Pendahuluan}

Tubuh manusia memiliki banyak sekali keunikan-keunikan, Salah satunya adalah wajah manusia, wajah manusia terdiri dari banyak sekali bagian-bagian yang masing-masing memiliki ciri tersendiri. Keunikan tersebut dimanfaatkan dalam ilmu komputer sebagai media untuk melakukan deteksi dan pengenalan terhadap fitur yang ada di wajah manusia. Dalam pengolahan cita untuk memperbaiki kualitas suatu gambar [1] dan mengolah informasi pada citra bisa dilakukans secara otomatis. Deteksi adalah menentukan keberadaan atau eksistensi sesuatu agar bisa dipelajari dan diolah menjadi informasi. Teknologi pengenalan wajah, Deteksi wajah, hidung dan mulut juga menjadi hal yang penting dalam teknologi pengenalan wajah. Dalam penerapan deteksi wajah, hidung, mulut dan mata ini dibangun menggunakan metode viola-jones [2] yang terdiri dari metode haar-like feature, citra integral, adaboost, dan cascade of classifier. Haar-Like Feature adalah fitur yang didasarkan pada Wavalet Haar [3] yang digunakan sebagai dasar untuk penentuan objek [4]. Citra integral adalah representasi tengah untuk citra dan terdiri dari jumlah nilai keabu-abuan dari citra $\mathrm{N}$ dengan tinggi y dan lebar x dimana nilai tiap pikselnya merupakan akumulatif dari nilai piksel atas dan kirinya yang digunakan untuk pendeteksian fitur secara cepat. Adaboost [5] merupakan sebuah metode boosting yang berfungsi untuk mencari fitur-fitur yang memiliki tingkat pembeda yang tinggi untuk dievaluasi terhadap data latih. Cascade Of Classifier merupakan sebuah classifier yang telah terlatih dengan ribuan contoh objek yang terdiri dari objek yang positif dan objek yang negatif. Haar Cascade Classifier adalah metode yang digunakan untuk mendeteksi objek [6]. Beberapa penelitian yang menggunakan metode viola-jones terutama sebagai pendeteksi wajah, Viola-Jones digunakan sebagai algoritma deteksi karena tingkat deteksi yang tinggi [7]. metode ini cepat dan tangguh untuk deteksi wajah yang 15 kali lebih cepat daripada teknik apa pun pada saat rilis dengan akurasi $95 \%$ [8].

Salah satu manfaat dari proses pengenalan wajah adalah mendapatkan informasi dari citra wajah [9] Metode Viola-Jones merupakan algoritma yang paling banyak digunakan untuk mendeteksi wajah, dimana proses pendeteksian wajah dilakukan dengan mengklasifikasikan sebuah gambar setelah sebelumnya melalui sebuah pengklasifikasi yang dibentuk dari data latih [10] karena wajah seseorang itu unik [11] dan memiliki ciri tersendiri.

\section{Metode Penelitian}

Metode yang digunakan dalam Penerapan Haar Cascade Classification Model Untuk Deteksi Wajah, Hidung, Mulut, Mata Menggunakan Algoritma Viola-Jones adalah dengan merancang tahapan rancangan penelitian untuk menghasilkan sistem yang bisa melakukan deteksi wajah, hidung, mulut dan mata seperti pada tahapan rancangan penelitian berikut ini:

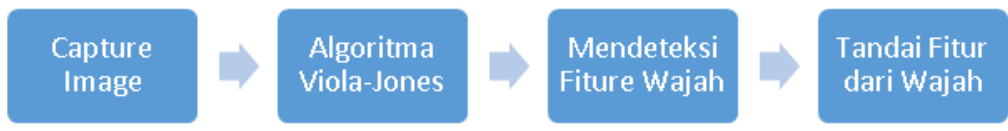

Gambar 1 Tahapan Rancangan Penelitian

\section{PEMBAHASAN}

Pada tahapan ini dijelaskan lebih rinci mengenai hasil Penerapan Haar Cascade Classification Model Untuk Deteksi Wajah, Hidung, Mulut, Mata Menggunakan Algoritma Viola-Jones dalam sebuah sistem yang bisa melakukan identifikasi Deteksi Wajah, 
Hidung, Mulut, Mata Menggunakan Algoritma Viola-Jones. Pada gambar 2 merupakan tampilan aplikasi untuk melakukan identifikasi identifikasi Deteksi Wajah, Hidung, Mulut, Mata dalam bentuk GUI.

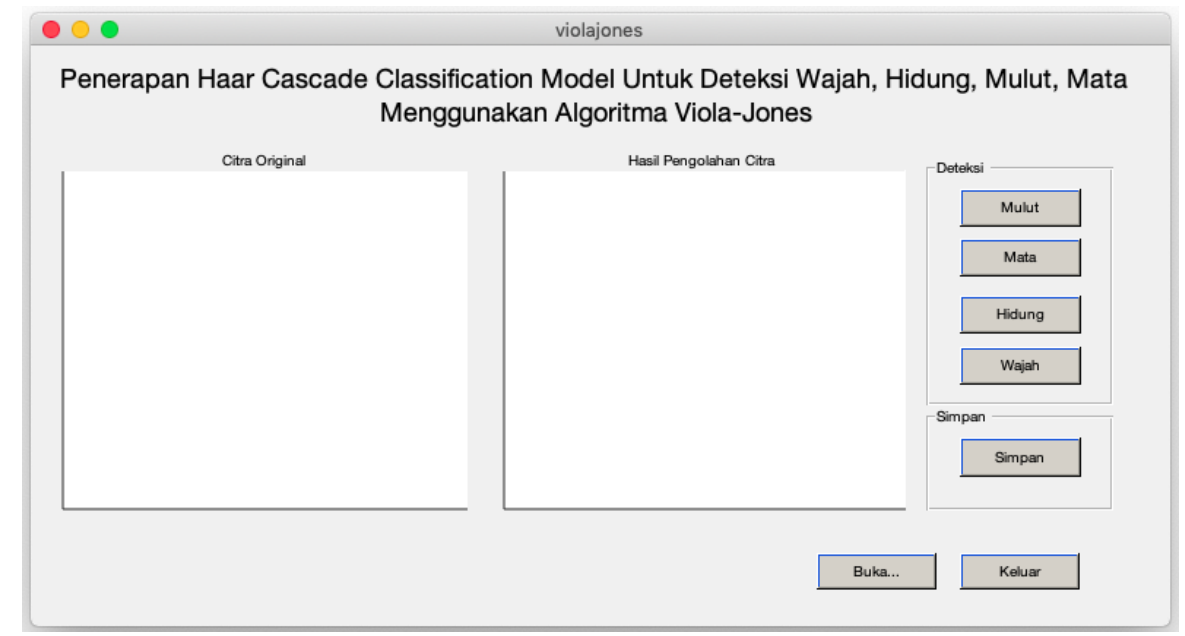

Gambar 2 Tampilan Aplikasi

\section{A. Deteksi Mulut}

Mulut merupakn salah satu organ tubuh manusia yang terdapat pada wajah, dalam melakukan pendeteksian mulut, digunakan haar fitur, model ini merupakan weak classifier [12] (Castrillón, Déniz, Guerra, \& Hernández, 2007), adapun untuk hasil Penerapan Haar Cascade Classification Model Untuk Deteksi Mulut Menggunakan Algoritma Viola-Jones adalah seperti pada Gambar3 dibawah ini:

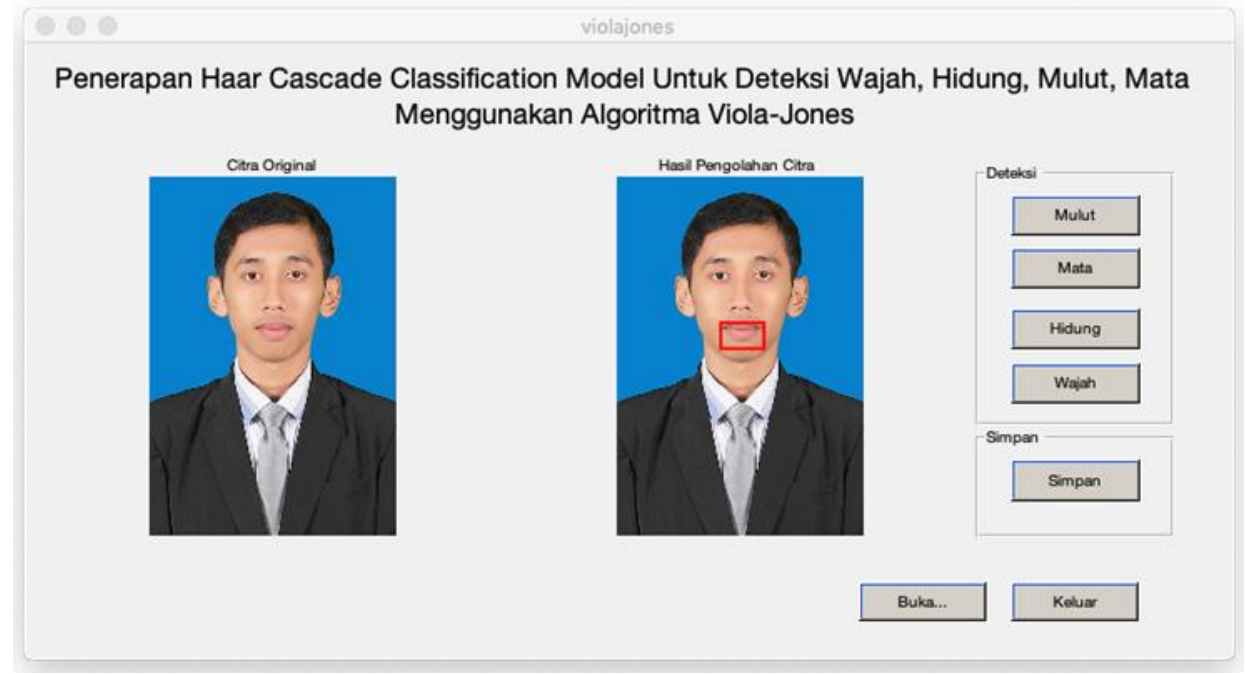

Gambar 3 Pendeteksian Mulut

Adapun untuk hasil pemotongan gambar mulut berdasarkan hasil analisis data citra yang di inputkan adalah seperti pada Gambar 4 berikut ini

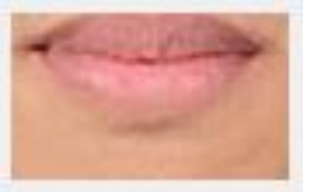

Gambar 4 Citra Mulut

\section{B. Deteksi Mata}

Mata merupakan salah satu ciri unik manusia yang terdapat pada wajah manusia, manusia memiliki sepasang mata yaitu mata bagian kiri dan mata bagian kanan. Dalm melakukan pendeteksian mata, system akan melakukan pendeteksian terhadap dua pasang mata sehingga nantinya akan dihasilkan identifikasi berupa penanda pada dua pasang mata seperti pada Gambar 5 di bawah ini: 


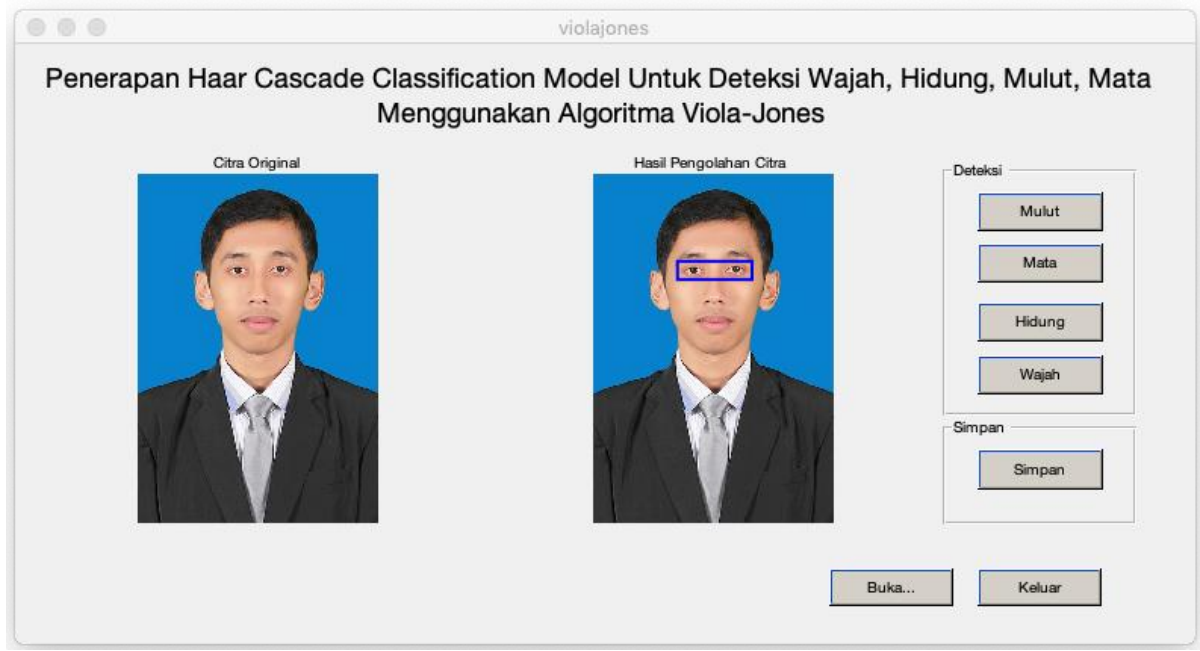

Gambar 5 Pendeteksian Mata

Sehingga hasil akhir dari proses pendeteksian mata adalah seperti pada Gambar 6 dibawah ini

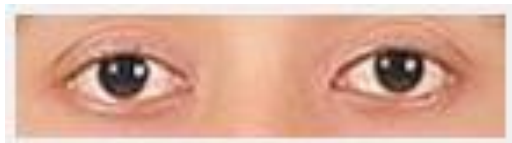

Gambar 6 Citra Mata

\section{Deteksi Hidung}

Salah satu ciri yang dimiliki seorang manusia pada wajah adalah Hidung, hidung selain sebagai alat indra penciuman dalam pengenalan wajah hidung juga bias dijadikan sebagai ciri dari wajah manusia. Model untuk pengenalan hidung menggunakan algoritma viola-jones ini merupakan weak classifier [13] (Castrillón et al., 2007). Adapaun untuk hasil deteksi hidung dapat dilihat pada Gambar 7 dibawah ini

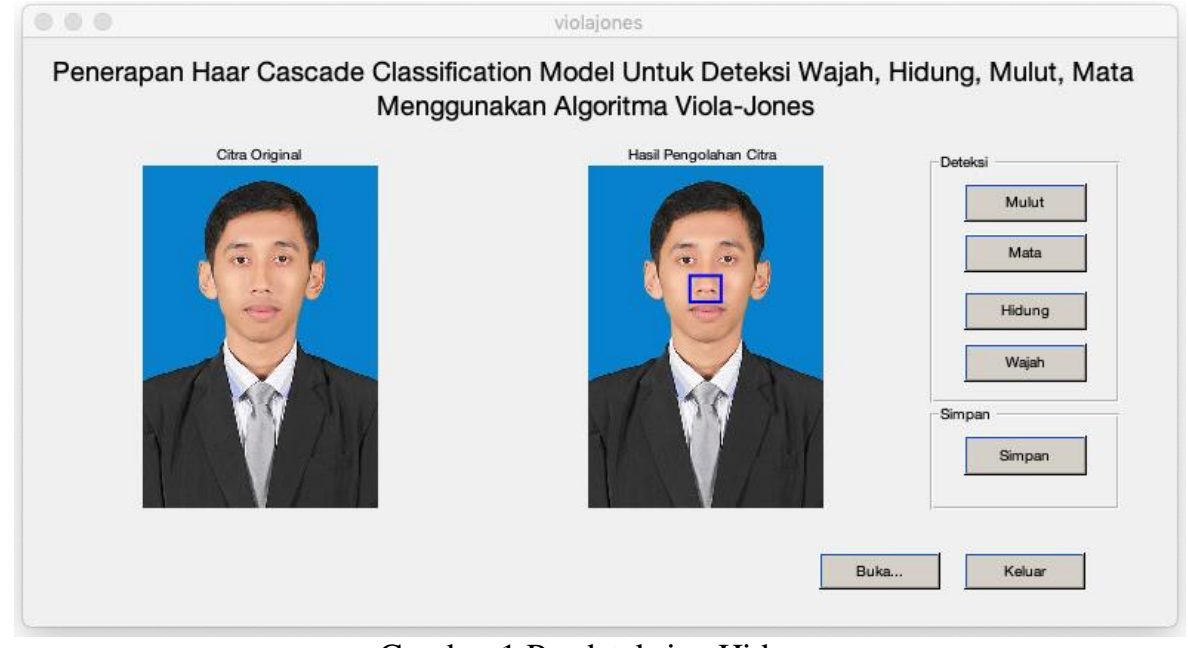

Gambar 1 Pendeteksian Hidung

Dan dibawah ini merupakan citra hidung yang berhasil di deteksi dari proses pendeteksian hidung pada Gambar 7 diatas.

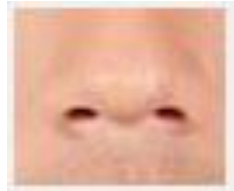

Gambar 2 Citra Hidung

\section{Deteksi Wajah}

Wajah merupakan bagian depan dari kepala yang meliputi mulut, mata, hidung, telinga, pipi, dahi dan bagian lain dari wajah yang memiliki ciri dan fungsi masing-masing, dengan algoritma viola-jones wajah bias dideteksi ketika menghadap kedepan dan keatas, dalam implementasinya menggunakan fitur haar untuk menyandikan fitur wajah dan pendeteksian wajah merupakan model dari weak classifiers[13]. Adapun untuk hasil pendeteksian wajah dengan mengggunakan algoritma viola-jones adalah seperti Gambar 9 dibawah ini 


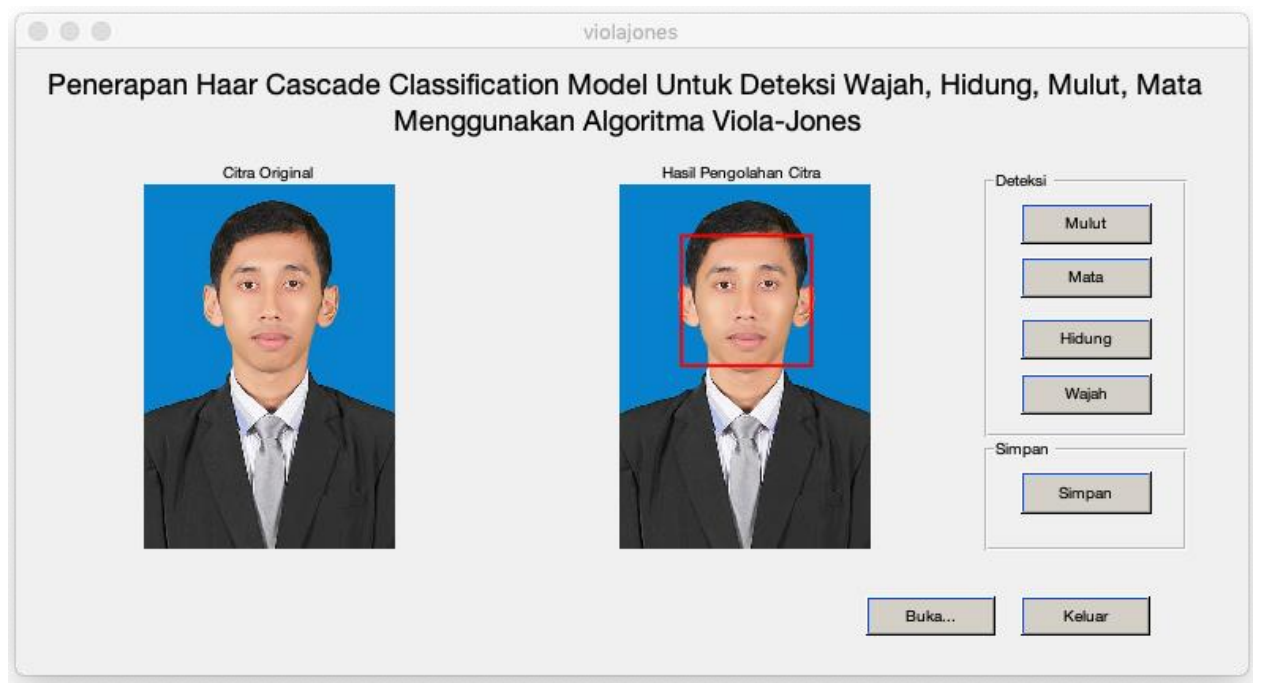

Gambar 9 Pendeteksian Wajah

Sedangkan untuk hasil deteksi wajah dapat dilihat pada Gambar 10 dibawah ini

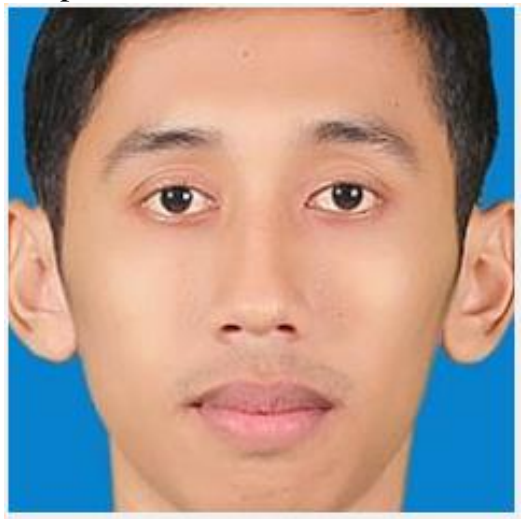

Gambar 10 Citra Wajah

\section{KESIMPULAN}

Pada penelitian ini disajikan pendekatan untuk melakukan Penerapan Haar Cascade Classification Model Untuk Deteksi Wajah, Hidung, Mulut, Mata Menggunakan Algoritma Viola-Jones sehingga didapatkan hasil berupa model sistem yang bisa mendeteksi objek-objek yang terdapat pada wajah manusia. Implemetasi algoritma Viola-jones dalam melakukan Deteksi Wajah, Hidung, Mulut, Mata menggunakan pemrograman Matlab mampu untuk mengidentifikasi objek-objek pada wajah sehingga bisa menandai fitur wajah yang ingin dideteksi sehingga bisa dilakukan pemotongan (Cropping) dari fitur wajah.

\section{KESIMPULAN}

Kesimpulan yang didapatkan pada penelitian ini adalah :

1. Berdasarkan percobaan yang dilakukan sebanyak 20 kali, didapatkan hasil akurasi dengan metode ekstraksi fitur warna dan euclidean distance adalah sebesar $75 \%$.

2. Proses klasifikasi kadar hidrasi tubuh dengan menggunakan citra ini dapat dipengaruhi oleh cahaya disekitar area yang dapat mempengaruhi hasil ekstraksi warna sehingga berdampak pada hasil pengujian.

3. Penelitian selanjutnya disarankan untuk meninjau dari sisi pengaruh cahaya atau menggunakan perangkat sensor yang diharapkan dapat memberikan hasil yang lebih baik.

\section{DAFTAR PUSTAKA}

[1] R. Mayasari and N. Heryana, "Reduce Noise in Computed Tomography Image using Adaptive Gaussian Filter," Int. J. Comput. Tech., vol. 6, no. 1, pp. 17-20, 2019, doi: 10.29126/23942231/IJCT-V6I1P4.

[2] K. Vikram and S. Padmavathi, "Facial parts detection using Viola Jones algorithm," in 2017 4th International Conference on Advanced Computing and Communication Systems (ICACCS), Jan. 2017, pp. 1-4, doi: 10.1109/ICACCS.2017.8014636. 
[3] P. Viola, M. Jones, and others, "Robust real-time object detection," Int. J. Comput. Vis., vol. 4, no. 34-47, p. 4, 2001.

[4] F. Lobban and S. Jones, Implementing the Viola-Jones Face Detection Algorithm, vol. 81, no. 4. 2008.

[5] Y.-Q. Wang, "An Analysis of the Viola-Jones Face Detection Algorithm," Image Process. Line, vol. 4, pp. 128-148, 2014, doi: 10.5201/ipol.2014.104.

[6] M. I. Ramadhani, A. E. Minarno, and E. B. Cahyono, "Vehicle Classification using Haar Cascade Classifier Method in Traffic Surveillance System," Kinetik, vol. 3, no. 1, p. 57, 2017, doi: 10.22219/kinetik.v3i1.546.

[7] N. T. Deshpande and S. Ravishankar, "Face Detection and Recognition using Viola-Jones algorithm and fusion of LDA and ANN," IOSR J. Comput. Eng., vol. 18, no. 6, pp. 1-6, 2016, [Online]. Available: https://pdfs.semanticscholar.org/c5cf/c1f5a430ad9c103b381d016adb4cba20ce4e.pdf.

[8] M. K. Dabhi and B. K. Pancholi, "Face Detection System Based on Viola - Jones Algorithm," Int. J. Sci. Res., vol. 5, no. 4, pp. 62-64, 2016, doi: 10.21275/v5i4.nov162465.

[9] I. Gangopadhyay, A. Chatterjee, and I. Das, "FACE DETECTION AND RECOGNITION USING HAAR CLASSIFIER AND LBP HISTOGRAM," Int. J. Adv. Res. Comput. Sci., vol. 9, no. 2, 2018.

[10] A. Suharso, "Pengenalan Wajah Menggunakan Metode Viola-Jones dan Eigenface Dengan Variasi Posisi Wajah Berbasis Webcam," TechnoXplore J. Ilmu Komput. dan Teknol. Inf., vol. 1, no. 2, pp. 19-30, 2017.

[11] S. Tikoo and N. Malik, "Detection of Face using Viola Jones and Recognition using Back Propagation Neural Network," Int. J. Comput. Sci. Mob. Comput., vol. 5, no. 5, pp. 288-295, 2016.

[12] M. Castrillón, O. Déniz, C. Guerra, and M. Hernández, "ENCARA2: Real-time detection of multiple faces at different resolutions in video streams," J. Vis. Commun. Image Represent., vol. 18, pp. 130-140, 2007.

[13] R. Lienhart, A. Kuranov, and V. Pisarevsky, "Empirical Analysis of Detection Cascades of Boosted Classifiers for Rapid Object Detection," in Pattern Recognition, 2003, pp. 297-304. 